immigrants is great. Most Pakistani girls are brought up in surroundings shunned by men. Most go to strict girls' schools, colleges, and even medical schools. Therefore most women find it hard to express themselves in front of men, let alone to be examined by a man for gynaecological reasons.

Secondly, I sadly admit that an appalling concept is prevalent even among educated men. They regard sons as a blessing and consider the woman responsible for the birth of the male child. A woman who cannot give birth to a boy in two or three deliveries can find her marriage in difficulties. Therefore a patient in labour enters in the labour room mostly without any antenatal care and frightened not only of the birth itself but also of the response of her husband and in laws in case a girl is born. During my final year I witnessed a woman who went into shock when she was told about the birth of her twin daughters. Such stress might contribute to the high maternal mortality. After that every new person in the labour room was instructed not to tell the patient about the sex of the baby unless her condition was pretty stable after the third stage of labour.

Thirdly, Pathans, the residents of the northern province, regard only sons as their true offspring. Hence a mother of two sons and two daughters would claim to have only two children. It has to be inquired into properly because this sort of misunderstanding once led to a senior house officer putting up an infusion of oxytocin for a grand multipara. Fortunately, no disaster ensued.

Finally, I was surprised that Dr Mann did not mention one big problem faced by the doctor on duty - that most of the patients do not remember their last menstrual period at all or remember it only in relation to a local fair or other event, sometimes making it impossible to calculate the likely date.

I hope these few words help doctors dealing with immigrant populations to understand the background to their problems and help the doctors to solve them. Many of these concepts do not have a religious base (and indeed not all Pakistanis share them) and thus can be helped by gentle and careful discussion.

University of Sussex

AMTUL RAZZAQ SAMI

Brighton BN1 90G

I Mann M. Relevance of experience abroad: obstetrics in Pakistan. BrMed f 1989;298:877-8. (1 April.)

\section{Plasma cholesterol, coronary heart disease, and cancer}

SIR, - It is of interest to consider the recent evidence' on cholesterol and cancer in a wider international context. In rural China plasma cholesterol concentrations are far lower than in the United Kingdom or United States and coronary heart disease is rare. A survey of mortality rates and of biochemical characteristics in 65 rural Chinese counties has recently been completed. ${ }^{2}$ In each county the plasma cholesterol concentration was estimated as the mean of a systematic sample of 100 men and women aged 35-64 in 1983. The overall mean was $3.3 \mathrm{mmol} / 1$. Counties were divided into three groups with respect to this estimate of plasma

Cancer mortality and plasma cholesterol in rural China

\begin{tabular}{ccccc}
\hline $\begin{array}{c}\text { Mean plasma } \\
\text { cholesterol in } 100 \\
\text { adults per county } \\
(\mathrm{mmol} / \mathrm{l})\end{array}$ & $\begin{array}{c}\text { No of rural Chinese } \\
\text { counties sampled } \\
\text { in this range of } \\
\text { cholesterol }\end{array}$ & $\begin{array}{c}\text { Average of county } \\
\text { cholesterol values } \\
\text { in } 1983\end{array}$ & $\begin{array}{c}\text { Average of county } \\
\text { cancer rates } \\
1973-5\end{array}$ & $\begin{array}{c}\text { Average of county } \\
\text { lung cancer rates } \\
\text { in 1973-5 }\end{array}$ \\
\hline$<3 \cdot 1$ & 23 & $2 \cdot 9$ & $8 \%$ & $0 \cdot 5 \%$ \\
$3 \cdot 1-3 \cdot 5$ & 23 & $3 \cdot 3$ & $8 \%$ & $0.5 \%$ \\
$>3 \cdot 5$ & 19 & $3 \cdot 8$ & $11 \%$ & $0.6 \%$ \\
\hline
\end{tabular}

${ }^{\star}$ Cumulative mortality from cancer by age 65 , in the absence of other causes of death. ${ }^{3}$ (The comparable figure of

England and Wales in $1973-5$ was $8 \%$.)

cholesterol, the middle group comprising 23 counties with mean plasma cholesterol $3 \cdot 1-3 \cdot 5$ $\mathrm{mmol} / \mathrm{l}$. There was no evidence that those with particularly low plasma cholesterol concentrations had high cancer rates (see table). This provides crude evidence that even cholesterol concentrations much lower than in Britain are not associated with any gross increase in cancer-indeed, if anything, the opposite trend was indicated.
R PETO

ICRF Cancer Studies Unit, University of Oxford,

Oxford OX $26 \mathrm{HE}$

J CHEN

Institute of Nutrition and Food Hygiene,

Chinese Academy of Preventive Medicine,

Beijing

Department of Cancer Epidemiology

Chinese Academy of Medical Science,

Beijing,

China

T C CAMPBELL

T BRUN

Department of Nutritional Biochemistry,

Cornell University,

Ithaca, New York

United States

1 Isles CG, Hole DJ, Gillis CR, Hawthorne VM, Lever AF. Plasm cholesterol, coronary heart disease, and cancer in the Renfrew and Paisley survey. Br Med I 1989;298:920-4. (1 April.)

2 Chen J, Campbell TC, Li J, Peto R. Diet, lifestyle and mortality in China. A study of the characteristics of 65 Chinese counties. Oxford: Oxford University Press (in press).

3 Day NE. Cumulative rates and cumulative risk. In: Waterhouse J, Muir C, Shanmugaratnam K, Powell J, eds. Cancer incidence in five continents. Vol IV. Lyons: International Agency for Research on Cancer, 1982:668-9.

\section{HDL as an independent risk factor in British men (and women)}

SIR, - The latest findings from the British regiona heart study ${ }^{1}$ show that high density lipoprotein (HDL) cholesterol is an independent risk factor for ischaemic heart disease in British men. This contrasts with the earlier report from this study, entitled "High density lipoprotein cholesterol is not a major risk factor for ischaemic heart disease in British men." $\mathrm{We}^{3}$ and others ${ }^{46}$ criticised the earlier study with regard to both the laboratory methods and data analysis and stated that the conclusions embodied in the title were premature. It is unfortunate that such a provocative title has entered the literature and has undoubtedly influenced current attitudes to this subject in the United Kingdom.

Dr John Betteridge's accompanying leading article is a useful summary of contemporary thinking,' emphasising as it does both the clinical value of high density lipoprotein cholesterol concentrations and the pitfalls associated with their measurement. Nevertheless, neither this editorial nor your recent one on the influence of oral contraceptives on lipid metabolism adequately addresses the issue of high density lipoprotein subfractions. This is particularly relevant when considering oral contraceptive
China Cancer Institue, users, who may have normal or even increased high density lipoprotein values despite a fall in the leve of the clinically more important $\mathrm{HDL}_{2}$ fraction."

Ischaemic heart disease is seen in patients without hypercholesterolaemia, and the investigation of other factors, particularly high density lipoprotein and its subfractions, remains important. ${ }^{10}$ This is especially so in women, in whom, as in men, ischaemic heart disease is the major cause of death and in whom high density lipoprotein cholesterol is a strong predictor of future disease."

D CROOK

I F GODSLAND

V WYNN

Cavendish Clinic,

London NW8 9SQ

1 Pocock SJ, Shaper AG, Phillips AN. Concentrations of high density lipoprotein cholesterol, triglycerides, and total cholesterol in ischaemic heart disease. $\mathrm{Br}$ Med $\mathcal{O}$ 1989;298: 998-1002. (15 April)

2 Pocock SJ, Shaper AG, Phillips AN, Walker M, Whitehead TP High density lipoprotein cholesterol is not a major risk factor for ischaemic heart disease in British men. Br Med $\mathcal{J}$ 1986;292:515-9.

3 Wynn V, Crook D, Godsland IF, Seed M, Shennan NM. High density lipoprotein cholesterol is not a major risk factor for
ischaemic heart disease in British men. Br Med J 1986;292: 1013.

4 Miller NE. High density lipoprotein cholesterol is not a majo risk factor for ischaemic heart disease in British men. BrMed 7 1986;292:1012.

5 Anonymous. HDL and ischaemic heart disease in Britain [Editorial]. Lancet 1986;i:481-2.

6 Anthony HM. High density lipoprotein cholesterol is not a major risk factor for ischaemic heart disease in British men. BrMed f 1986;292:1199.

7 Betteridge DJ. High density lipoprotein and coronary heart disease. BrMed ₹ 1989;298:974-5. (15 April)

8 Fotherby K. Oral contraceptives and lipids. BrMed f 1989;298: $1049-50$

$9 \mathrm{Wynn}$ V, Godsland I, Simpson R, et al. Carbohydrate and lipid metabolism in low-dose oral contraception. In: Proceedings of XIIth world congress of obstetrics and gynaecology. Carnforth: Parthenon Publishing (in press).

10 Kannel WB. Cholesterol and risk of coronary heart disease and mortality in men. Clin Chem 1988;34:53-9.

11 Crouse JR. Gender, lipoproteins, diet, and cardiovascular risk. Lancet 1989;i:318-20.

\section{Omeprazole and cimetidine in treating ulcers of the body of the stomach}

SIR,-The Danish Omeprazole Study Group showed that omeprazole ( $30 \mathrm{mg} /$ day) is just as effective as cimetidine ( $1 \mathrm{~g} /$ day) in healing gastric body ulcers, even though the $95 \%$ confidence intervals were in favour of omeprazole at four weeks of treatment.

In the first controlled study comparing omeprazole with another $\mathrm{H}_{2}$-receptor antagonist ranitidine in a subgroup of patients with gastric body ulcers the two drugs induced similar healing rates. ${ }^{2}$ In contrast, in a recent trial omeprazole not only healed gastric ulcers better than ranitidine but also was superior at a dose of $40 \mathrm{mg} /$ day than $20 \mathrm{mg} /$ day. On the basis of this finding the Danish Omeprazole Study Group argued that the comparable data obtained with omeprazole and cimetidine might be owing to the use of omeprazole at $30 \mathrm{mg} /$ day and speculated that a dose of $40 \mathrm{mg} /$ day might have improved the results.

Is there really, however, a pathophysiologic rationale in using high doses of omeprazole in these types of patients? Firstly, omeprazole $30 \mathrm{mg} /$ day is the optimal dose for a maximal decrease of 24 hou gastric acidity. ${ }^{4}$ Secondly, patients with ulcers in the body of the stomach generally have lower than normal rates of acid secretion, ${ }^{5}$ and thus extremely potent doses of antisecretory drugs should not be necessary. As the only therapeutic effect of omeprazole is in suppressing acid secretion the results of Walan et al are surprising ${ }^{3}$; proposing such a high dose for treating ulcers of the body of the stomach does not seem to be advisable. The 
conflicting results obtained in these controlled trials on the efficacy of omeprazole in gastric body ulcers may conceivably depend on the fact that this drug acts only partially through correcting the pathophysiological alterations that seem to predominate in this disease.

V SAVARINO G S MELA G CELLE

Istituto Scientifico di Medicina Interna,

Cattedra di Gastroenterologia e Clinica Medica R,

Università de Genova,

16132 Genova, Italy

1 Danish Omeprazole Study Group. Omeprazole and cimetidine in the treatment of ulcers of the body of the stomach: a doub blind comparative trial. Br Med f 1989;298:645-7. (11 March.)

2 Classen M, Dammann HG, Domschke W, et al. Abheilungsrate nach Omeprazol- und Ranitidine-behandlung des Ulcus ventriculi. Ergebnisse einer deutschen Multizenterstudies. Dtsch Med Wochenschr 1985;110:628-33.

3 Walan A, Bader JP, Classen M, et al. Effect of omeprazole and ranitidine on ulcer healing and relapse rates in patients with ranitidine on ulcer healing and relapse rates in paten
benign gastric ulcer. $N$ Engl $\mathcal{H}$ Med 1989;320:69-75.

4 Sharma BK, Walt RP, Pounder RE, Gomes MdeFA, Wood EC

Logan LH. Optimal dose of oral omeprazole for maximal 24 hour decrease of intragastric acidity. Gut 1984:25:957-64.

5 Johnson HD, Love AHG, Rogers NC, Wyatt AP. Gastric ulcers, blood groups and acid secretion. Gut 1964;5:402-11.

\section{Dopa responsive dystonia}

SIR, - The onset after birth and the progressive course of the illness in the patients reported by Drs Kathryn Boyd and Victor Patterson' do not necessarily preclude a diagnosis of cerebral palsy.

Motor patterns may occasionally change with time in patients with cerebral palsy. ${ }^{2}$ Several authors have emphasised that, although cerebral palsy is usually due to a non-progressive cerebra insult, the clinical expression is not inevitably unchanging, or non-progressive. ${ }^{24}$ The evolution from hypotonia in early infancy to spasticity in later life has been well documented. ${ }^{5}$ Progressive dystonia or choreoathetosis, or both, may develop within the first two decades in children who appear initially to have a static encephalopathy. In the patient reported by Montagna et al abnormal movements developed in the fifth year of life after birth anoxia; the movements progressively worsened and were resistant to drug treatment, including levodopa."

In contrast to the lesson given by Drs Boyd and Patterson that dopa responsive dystonia may be misdiagnosed as cerebral palsy, other authors ${ }^{3}$ have emphasised the converse-for example, that some patients diagnosed as having dystonia musculorum deformans (and presumably also dopa responsive dystonia) may have cerebral palsy. Clearly, the differential diagnosis of early onset and progressive dystonia must include both disorders.

R E APPLETON

Princess Mary Maternity Hospital

Newcastle upon Tyne NE2 3BD

I Boyd K, Patterson V. Dopa responsive dystonia: a treatable condition misdiagnosed as cerebral palsy. $\mathrm{Br}$ Med $\mathcal{F}$ 1989;298 1020-1. (15 April.)

2 Hanson R A, Berenberg W, Byers RK. Changing motor pattern in cerebral palsy. Develop Med Child Neurol 1970;12:309-14.

3 Burke RE, Fahn S, Gold AP. Delayed onset dystonia in patients with "static encephalopathy." I Neurol Neurosurg Psychiatry 1980;43:789-97.

4 Montagna P, Cirignotta F, Gallassi R, Sacquegna T. Progressive choreo-athetosis related to birth anoxia. I Neurol Neurosur Psychiatry 1981;44:957.

5 Byers RK. Evolution of hemiplegias in infancy. Am $\mathcal{J}$ Dis Child 1941;61:915-27.

SIR, - We have recently come across another case of dopa responsive dystonia,' which had this time been labelled as psychogenic.

A 24 year old woman developed inversion posturing of the right foot at the age of 12 such that her shoe was rapidly worn down along the outstep. By 17 her right leg had stiffened and she walked with the ankle plantar flexed. Over the next three years the left leg became similarly affected and she appeared to be walking on tiptoe. A notable feature was the considerable variability in the symptoms. She was seen by several consultants in various specialties, and at the age of 19 a psychogenic disorder was diagnosed. In the five years before presenting to us her gait became even more bizarre with opisthotonic like arching of the spine, such that she required support to walk to prevent her falling over backwards. The symptoms remained variable. There was no family history of any movement disorder. Examination confirmed abnormal posturing in the sitting position, but careful assessment of tone did not reveal any extrapyramidal increase. There was no bradykinesia.

The patient started taking Sinemet 110 (levodopa $100 \mathrm{mg}$, carbidopa $10 \mathrm{mg}$ ), one tablet three times a day, and after two weeks was walking almost normally. Withdrawing the Sinemet caused symptoms to recur after four days and its reintroduction rapidly led to their resolution. The patient has remained well and in full time employment with this treatment.

The misdiagnosis of dystonia as a psychiatric disorder is well recognised. ${ }^{2}$ Progressive dystonia with diurnal fluctuation is also very uncommon (three out of 932 patients with dystonia in one series $^{3}$ ). In our experience dystonia is rarely misdiagnosed as cerebral palsy and is much more commonly thought to be psychogenic, particularly in the early stages. We agree with Drs Boyd and Patterson that a greater awareness of dopa responsive dystonia is needed and would include psychiatrists as another group requiring some knowledge of this condition. However, as it is so uncommon, referral to a neurologist should be essential to allow greater treatment experience to emerge.

D J BURN

Department of Neurology N E F CARTLIDG

Newcastle upon Tyne NE1 4LP

1 Boyd K, Patterson V. Dopa responsive dystonia: a treatable condition misdiagnosed as cerebral palsy. $\mathrm{Br}$ Med $\mathcal{f}$ 1989;298: 1019-20. (15 April.)

2 Lesser RP, Fahn S. Dystonia: a disorder often misdiagnosed as a conversion reaction. Am $\mathcal{F}$ Psych 1978;153:349-52.

3 Fahn S, Marsden CD, Calne DB. Classification and investigation of dystonia. In: Marsden CD, Fahn S, eds. Movement disorders 2. London: Butterworth, 1987 .

\section{Practice annual report}

SIR, - The advice given by Dr Stefan Cembrowicz ${ }^{1}$ is timely in view of the government's proposals for making the production of an annual report part of every general practitioner's terms and conditions of service.

We thoroughly endorse his observation that producing an annual report acts as "a painless introduction to simple performance review." We were, however, rather disappointed to find only a passing mention of short or long term objectives for his practice.

In the Oxford general practice outcomes project a framework is being developed whereby an annual report is centred on a set of mutually agreed objectives. The objectives might be long term and overarching - for example, to improve access to services offered by the practice-or short term and specific-for example, to establish a diabetic register in 1989.

The objectives are related to the skills that the practice staff should possess, and they should encompass the three aspects of the service that contribute to good quality care - the structure or resources of the practice, the process or activity of the practice, and the outcome or results. The last of the three is the most difficult to measure but is in our opinion the most crucial aspect of quality.
As it would not be possible or even desirable to audit every objective every year establishing a set of "tracer" objectives that encompass structure, procèss, and outcome and relate to different skills in different areas of the service is advisable. These objectives might be changed every few years to prevent boredom. Setting objectives, making them central to the annual report, and reviewing progress towards them subsequently helps to establish a clear framework in which all those who work in the practice can strive to improve quality. We are interested to hear about other work on objective led annual reports.

BRIAN KEEBLE

C A CHIVERS

Oxford OX2 6NW

1 Cembrowicz S. How to do it. Write a practice annual report. BrMed f 1989;298:953-4. (8 April.)

2 Department of Health and Welsh Office. General practice in the National Health Service: a new contract. London: DoH, 1989.

\section{Burns from a tumble drier}

SIR,-With respect to the article by Messrs $\mathrm{K}$ Herbert and S K Varma' I would like to report on a 3 year old girl, who presented at this hospital's casualty department in September 1988.

Apparently, she had been playing that evening and her clothes had been wet. She placed these in the tumble drier and then climbed in herself, managing to close the door behind her. Her father found her and brought her to the hospital, a delay of about 10 minutes, where I was the senior house officer on duty. On arrival she was diagnosed as having a cardiorespiratory arrest. She was resuscitated and intubated, but although she developed a cardiac output, she never showed spontaneous respiration. There was evidence that she had vomited and aspirated and there were full thickness burns to her hands and buttocks. She remained hypotensive despite vigorous fluid replacement with plasma protein fraction and crystalloid. She was then transferred to the regional paediatric unit, the Royal Belfast Hospital for Sick Children, where she was found to have developed a disseminated intravascular coagulopathy, and she subsequently died that night. I wholly agree, therefore, with the recommendations of Messrs Herbert and Varma for greater safety precautions with these domestic appliances.

MAEVE LAMBE

Daisy Hill Hospital,

Newry, County Down, Northern Ireland

1 Herbert K, Varma SK. Burns from a tumble drier. Br Med $\mathcal{f}$ 1989;298:571. (4 March.)

\section{Tetrahydroaminoacridine in Alzheimer's disease}

SIR,-Dr Jane Byrne and Professor Tom Arie's editorial' ${ }^{1}$ prompts us to report the effect of physostigmine in another poorly understood syndrome, that of Cheyne-Stokes respiration. We suggest that this might be an expression of a similar deficit in the cholinergic system.

After a mild left hemiparesis a frail $\mathbf{9 2}$ year old normotensive woman who was taking digitalis for atrial fibrillation developed ischaemic gangrene of her right foot and leg. The leg was amputated through the knee without preoperative medication under spinal analgesia. She was alert and cheerful throughout, vital signs were unaffected, and blood loss was minimal.

Two hours after the operation, after the effects of the analgesia had worn off, she became stuporous with Cheyne-Stokes respiration (Glasgow coma scale score $>8^{2}$ ). She was cold and clammy (axillary temperature $35 \cdot 6^{\circ} \mathrm{C}$ ), and she had pinpoint pupils. Her pulse rate and volume and 